\title{
The Effects of Motor Coordination Error Duration on Reaction Time and Motivational Achievement Tasks among Young Romanian Psychology Students
}

\author{
Mihai Aniței and Mihaela Chraif
}

\begin{abstract}
Present study is focused on highlighting the effects of motor coordination error duration on reaction time to multiple stimuli, on motivation from competition and on motivation from personal goals among young psychology students. Method: the participants were 65 undergraduate students, aged between 19 and 24 years old $(m=21.65 ;$ S.D. $=$ 1.49), 32 male and 33 female, all from the Faculty of Psychology and Educational Sciences, University of Bucharest, Romania. Instruments were the Determination test, the Objective Achievement Motivation Test, and the two hand coordination test. Results: The first and sixth hypotheses were confirmed. According to these findings, there are statistically significant overall mean error duration differences in motivation from competition in young psychology students $(t=2.13 ; p=0.037<0.05)$ and there are statistically significant overall mean error duration differences in correct reactions to multiple stimuli in young psychology students $(t=2.0001 ; p=0.049<0.05)$. Future research on motivation from competition and on motivation from personal goals should relate anxiety level motivation achievement and performance impairment in competition.
\end{abstract}

Index Terms-Aspiration level, motivation from personal goals, motivation from competition, incorrect reactions to the stimuli.

\section{INTRODUCTION}

In the academic environment, performance can be measured and evaluated objectively using performance evaluation scales or with grades. Nevertheless, when it comes to self-assessment, academic performance also contains a subjective component.

In addressing the concept of performance, we analyze specific goals, intrinsic motivation, extrinsic motivation, self-determination, motivation from competition, motivation from specific goals, aspiration level and many other variables. Hence, [1] show that specific goals allow individuals to identify the specific behaviors they need for successful achievement of goals. [2], [3], cited by [4], highlighted that intrinsic motivation is related to more positive affective experiences, associated with deeper level learning, higher grades and use of meta-cognitive strategies. Therefore, [5], [6]

Manuscript received December 10, 2012; revised February 18, 2013.

M. Aniței is with the Doctoral School, Coordinator of Experimental Psychology Laboratory Faculty of Psychology and Educational Sciences, University of Bucharest, President of Collegium of Psychologists, Romania (e-mail: anitei_mihai@yahoo.com).

M. Chraif is with the Work and Transportation Psychology Laboratory, Coordinator of Master program "Management of training psychologists in work, transportation and services psychology" Faculty of Psychology and Educational Sciences, University of Bucharest, Romania (e-mail: mihaelapopa14@yahoo.com). and [7], cited by [4], show that according to the Self-Determination Theory, motivation varies from intrinsic to external regulation (extrinsic motivation). [8] Highlighted that the theory of efficient processing offers an explanation of why performance changes under pressure. [9] Cited by [10], show that the theory of efficient processing, as an attention theory, highlights the effects of anxiety on performance changes. Furthermore, [11], cited by [10], show that individuals experience negative emotions on working memory while competing.

\section{OBJECTIVES AND HyPOTHESES}

\section{A. Objectives}

The objectives of the experimental research are the following:

1) To highlight the effects of overall mean error duration on reaction time to multiple stimuli in young psychology students.

2) To highlight the effects of overall mean error duration on motivation from competition test in young psychology students.

3) To highlight the effects of overall mean error duration on motivation from personal goals in young psychology students.

\section{B. Hypotheses}

The research hypotheses are the following:

1) There are statistically significant overall mean error duration differences in motivation from competition in young psychology students.

2) There are statistically significant overall mean error duration differences in self-motivation to complete an individual task (baseline) in young psychology students.

3) There are statistically significant overall mean error duration differences in motivation from personal goals in young psychology students.

4) There are statistically significant overall mean error duration differences in aspiration level in young psychology students.

5) There are statistically significant overall mean error duration differences in correct reactions to multiple stimuli in young psychology students.

6) There are statistically significant overall mean error duration differences in incorrect reactions to multiple stimuli in young psychology students.

7) There are statistically significant overall mean error duration differences in omitted reactions to multiple 
stimuli in young psychology students.

\section{METHOD}

\section{A. Participants}

The participants were 65 undergraduate students, aged between 19 and 24 years old ( $m=32 ;$ S.D.=33), 32 male and 33 female from the Faculty of Psychology and Educational Sciences, University of Bucharest, Romania.

\section{B. Instruments}

The Determination test [12]. The test measures stress tolerance to repeated visual and audio stimuli and the ability to react to them. The test requires participants' cognitive skills to distinguish different colors and sounds and to select the relevant responses.

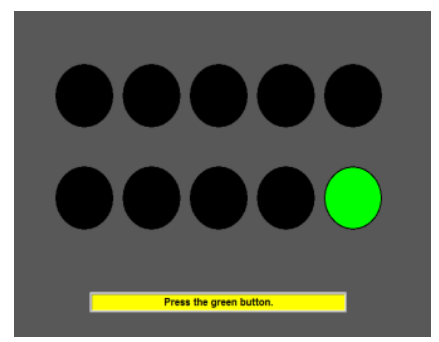

Fig. 1. Example of stimuli sequence from DT test [12].

The Objective Achievement Motivation Test (OLMT) [12] is a computerized test measuring achievement motivation. It provides information about individual competitive performance constraints.

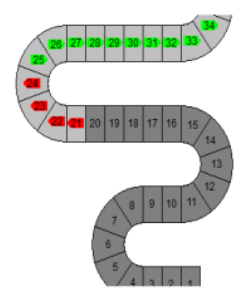

Fig. 2. Example of stimuli sequence from OLMT test measuring motivation facing individual goals [12].

Fig. 2 illustrates an example of stimuli sequence from the OLMT test measuring motivation while completing individual goals. The participants achieve the tasks according to personal goals to complete more or less of the exercise, with higher or lower speed.

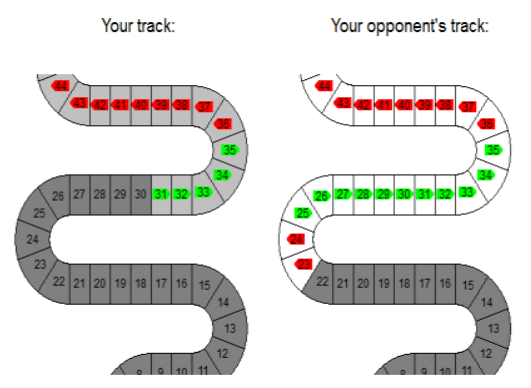

Fig. 3. Example of stimuli sequence from OLMT test measuring motivation from competition [12].
Fig. 3 illustrates an example of stimuli sequence from the OLMT test measuring the level of motivation from competition. The participants perform the tasks comparing themselves with the competitor's speed and accuracy in the task of completing more or less of the exercise, with higher or lower speed.

Two hand coordination tests [12] measure the speed and accuracy of coordination when making small, fine movements. The task is to move a red spot along a gray track. The task can be completed either with two control knobs or two joysticks. According to the test handbook this test focuses on two components of human ability: eye-hand coordination and coordination between left and right hand [14].

Fig. 4 presents the task of modeling the red spot's trajectory along the gray track.

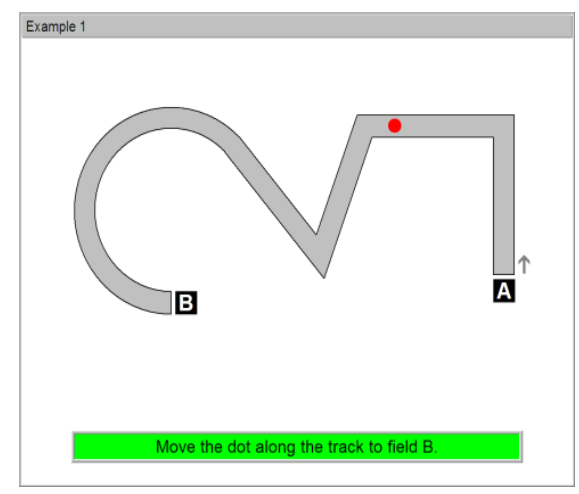

Fig. 4. Example of stimuli sequence for the 2-hand coordination test [12].

\section{Procedure}

In the first phase, the participants completed the informed consent form. In the second phase of the experiment, the participants applied the tests as described in "Method". All three psychological tests provide step by step instructions. They also have an exercise phase before the test application.

\section{Experimental Design}

The dependent variables for the Determination test (reaction time to multiple stimuli) are: the number of correct reactions to stimuli, the number of incorrect reactions to stimuli and the number of omitted reactions to stimuli.

The dependent variables for the Objective Achievement Motivation Test are: the baseline (motivation to perform the task as well and as quickly as possible, with a high percentile rank indicating when the participant is well motivated to perform the simple task), the motivation from personal goals (measures the extent to which the participant modifies his performance by setting goals for his results), the aspiration level (highlights the extent to which the goal set by the participant is overtaken or undertaken), the motivation from competition (a high percentile ranks shows that the competitive situation produces an above average increase in performance comparing with the baseline).

The dependent variables for the Two Hand Coordination test are: the overall mean of task completion (this variable measures the average time taken to move the red spot among the track), the overall mean of the error duration (this variable represents the time during which the point was outside the tolerance limit defined by the track area) and the overall percent error duration (this variable represents the ratio of the 
total error duration to the total task duration).

\section{RESULTS}

After collecting the data from all the participants to the three tests applications, the Kolmogorov-Smirnov test was used to verify if the data is normally distributed. As normal distributions for all the variables were obtained $(p>0.05)$, the $\mathrm{t}$-test was applied to the independent groups. The participants were divided into two groups (categories) using the overall percent error duration variable. The first group/category, between $0 \%$ and $38 \%$, is characterized by low capacity to convert very small deviations from the intended route into the appropriate compensatory movement. The second category, between $38 \%$ and $100 \%$, is characterized by high capacity to convert very small deviations from the intended route into the appropriate compensatory movements. Furthermore, as the overall percent error duration variable highlights, the individuals that obtained high scores (more than 38\%) have high precision of motor coordination and high accuracy of information processing. The individuals that obtained low scores (less than 38\%) have low precision of motor coordination and low accuracy of information processing [12].

In order to test the hypotheses, the t-test was applied to highlight the effects of overall percent error duration among the number of correct reactions to stimuli, the number of incorrect reactions to stimuli, the number of omitted reactions to stimuli, the baseline, motivation from personal goals, aspiration level, and motivation from competition.

TABLE I: DESCRIPTIVE STATISTICS (OLMT TEST)

\begin{tabular}{|c|c|c|c|}
\hline Variables & $\begin{array}{l}\text { Overall percent } \\
\text { error duration } \\
\text { (Binned variable } \\
\text { percentile) }\end{array}$ & Mean & $\begin{array}{l}\text { Standard } \\
\text { deviation }\end{array}$ \\
\hline \multirow{2}{*}{ Baseline } & $<=38$ & 65.62 & 25.09 \\
\hline & $38-100$ & 70.40 & 21.13 \\
\hline \multirow[t]{2}{*}{$\begin{array}{l}\text { Motivation from } \\
\text { personal goals }\end{array}$} & $<=38$ & 40.46 & 29.21 \\
\hline & $38-100$ & 44.56 & 28.20 \\
\hline \multirow[t]{2}{*}{ Aspiration level } & $<=38$ & 55.25 & 30.09 \\
\hline & $38-100$ & 51.65 & 25.34 \\
\hline \multirow[t]{2}{*}{$\begin{array}{l}\text { Motivation from } \\
\text { competition }\end{array}$} & $<=38$ & 34.81 & 26.60 \\
\hline & $38-100$ & 21.65 & 22.63 \\
\hline
\end{tabular}

Table I illustrates the descriptive statistics for the OLMT test variables: Baseline, Motivation from personal goals, Aspiration level, and Motivation from competition.

TABLE II: DESCRIPTIVE STATISTICS (DETERMINATION TEST)

\begin{tabular}{|l|l|l|l|}
\hline & $\begin{array}{l}\text { Overall percent } \\
\text { error duration } \\
\text { Variables }\end{array}$ & $\begin{array}{l}\text { Mean } \\
\text { percentile) }\end{array}$ & $\begin{array}{l}\text { Standard } \\
\text { deviation }\end{array}$ \\
\hline Correct reactions & $<=38$ & 56.59 & 22.32 \\
\hline & $38-100$ & 57.84 & 22.85 \\
\hline Incorrect reactions & $<=38$ & 30.00 & 23.44 \\
\hline & $38-100$ & 20.37 & 14.34 \\
\hline Omitted reactions & $<=38$ & 15.43 & 14.48 \\
\hline & $38-100$ & 12.15 & 14.73 \\
\hline
\end{tabular}

Table II illustrates the descriptive statistics for the Determination test variables: number of correct reaction to stimuli, number of incorrect reactions to stimuli and number of omitted reactions to stimuli.

In order to test the hypotheses, the t-test for independent groups was applied (see Table III and Table IV).

Table III illustrates the t-test values and the p-values of the overall percent error duration differences among the variables of the OLMT test.

TABLE III: T-TEST VALUES AND P-VALUE (OLMT TEST)

\begin{tabular}{|c|c|c|c|}
\hline Variables & $\begin{array}{l}\text { Overall percent } \\
\text { error duration } \\
\text { (Binned variable } \\
\text { percentile) }\end{array}$ & $\begin{array}{l}\text { T-test } \\
\text { value }\end{array}$ & $\mathrm{p}$-value \\
\hline \multirow[t]{2}{*}{ Baseline } & $<=38$ & -0.82 & 0.413 \\
\hline & $38-100$ & & \\
\hline \multirow[t]{2}{*}{$\begin{array}{l}\text { Motivation from } \\
\text { personal goals }\end{array}$} & $<=38$ & -0.57 & 0.571 \\
\hline & $38-100$ & & \\
\hline \multirow[t]{2}{*}{ Aspiration level } & $<=38$ & 0.51 & 0.607 \\
\hline & $38-100$ & & \\
\hline \multirow[t]{2}{*}{$\begin{array}{l}\text { Motivation from } \\
\text { competition }\end{array}$} & $<=38$ & 2.13 & 0.037 \\
\hline & $38-100$ & & \\
\hline
\end{tabular}

As can be seen in Table III, the first hypothesis "There are statistically significant overall mean error duration differences in motivation from competition in young psychology students" was confirmed $(t=2.13 ; p=0.037<0.05)$. Furthermore, the young psychology students that obtained high scores (more than 38\%) with high precision of motor coordination and high accuracy of information processing also obtained lower scores by a statistically significant margin in motivation from competition variable than the young students at psychology that obtained low scores (less than $38 \%$ ) with low precision of motor coordination and low accuracy of information processing $\quad(21.65<34.81$; $p=0.037<0.05$ ). Hypotheses number 2,3 , and 4 , regarding the statistically significant differences of the overall mean error duration on self-motivation to complete an individual task, motivation from personal goals and the aspiration level on young psychology students were not confirmed (see table III, $p>0.05)$.

Table IV shows the t-test values and the p-values for overall percent error duration differences among the variables of the Determination test.

TABLE IV: T-TEST VALUES AND P-VALUE (DETERMINATION TEST)

\begin{tabular}{|l|l|l|l|}
\hline \multirow{2}{*}{ Variables } & $\begin{array}{l}\text { Overall percent } \\
\text { error duration } \\
\text { (Binned variable } \\
\text { percentile) }\end{array}$ & $\begin{array}{l}\text { T-test } \\
\text { value }\end{array}$ & p-value \\
\hline Correct reactions & $<=38$ & -0.22 & 0.826 \\
\hline & $38-100$ & & \\
\hline Incorrect reactions & $<=38$ & 2.00 & 0.049 \\
\hline & $38-100$ & & \\
\hline Omitted reactions & $<=38$ & 0.89 & 0.373 \\
\hline & $38-100$ & & \\
\hline
\end{tabular}

The sixth hypothesis "There are statistically significant 
overall mean error duration differences in incorrect reactions to multiple stimuli in young psychology students" has been confirmed $(t=2.0001 ; p=0.049<0.05)$. Hence, as Table II and Table IV show, the young psychology students that obtained high scores (more than 38\%) with high precision of motor coordination and high accuracy of information processing also obtained lower scores by a statistically significant margin at the incorrect reactions variable than the young psychology students that obtained high scores at the incorrect reactions variable with low precision of motor coordination and low accuracy of information processing (less than 38\%) $(21.65<34.81 ; p=0.037<0.05)$. Also, Table II and Table IV illustrate that hypotheses number 5 and number 7 were not confirmed $(p>0.05)$.

\section{CONCLUSION}

Findings highlight that the effects of overall percent error duration on young psychology students' motivation from competition are different by a statistically significant margin according to the precision of motor coordination and high accuracy of information processing category (low scores between $0 \%$ and $38 \%$; high scores between $38 \%$ and $100 \%$ ). Hence, as the first hypothesis has been confirmed $(t=2.13$; $p=0.037<0.05$ ), young psychology students with low precision of motor coordination and low accuracy of information processing are more likely to obtain high scores at motivation from competition while completing the tasks with a competitor at the same time (Fig. 3). Furthermore, findings highlight that young students with high precision of motor coordination and high accuracy of information processing category are less implicated in achieving high scores at motivation from competition while completing the tasks with a competitor. Taking into consideration that the OLMT test measures personality traits related with motivation from competition, these findings show that young psychology students with low precision of motor coordination and low accuracy of information processing evidence higher implication in competition than the other category. Hence, they tend to be strongly implicated in competing to obtain a higher performance with a higher consumption of energy. In addition, table I shows that the group/category of young psychology students with low precision of motor coordination and low accuracy have the aspiration group mean level higher than the group/category of young psychology students with high precision of motor coordination and high accuracy $(55.25>51.65)$. Furthermore, the motivation from competition variable implies pressure from the competitor and from the task's time limit. Future research on motivation from competition and motivation from personal goals should relate anxiety level with motivation achievement and performance impairment in competition and applications of processing efficiency theory [10], [13].

\section{ACKNOWLEDGMENT}

This work was supported by the strategic grant
POSDRU/89/1.5/S/62259, Project "Applied social, human and political sciences", Postdoctoral training and postdoctoral fellowships in social, human and political sciences" co-financed by the European Social Fund within the Sectorial Operational Program Human Resources Development 2007-2013.

\section{REFERENCES}

[1] E. A. Locke and G. P. Latham, A theory of goal setting and task performance, Englewood Cliffs, NJ: Prentice-Hall, 1990.

[2] B. Soenens and M. Vansteenkiste, "Antecedents and outcomes of self-determination in three life domains: The role of parents' and teachers' autonomy support," Journal of Youth and Adolescence, vol. 34, pp. 589-604, 2005.

[3] M. Vansteenkiste, M. Zhou, W. Lens, and B. Soenens, "Experiences of autonomy and control among Chinese learners: Vitalizing or immobilizing?" Journal of Educational Psychology, vol. 97, pp. 468-483, 2005.

[4] A. P. Hill, "Motivational Vulnerability in First Year Undergraduates: A Self-Determination Perspective, Final Report Dr. Andrew P. Hill York St. Hospitality," Leisure, Sport and Tourism Network, September 2011.

[5] E. L. Deci, R. J. Vallerand, and L. G. Pelletier, "Motivation and Education: The Self-Determination Perspective," Educational Psychologist, vol. 26, no. 3-4, pp. 325-346, 1991.

[6] R. M. Ryan and E. L. Deci, "Intrinsic and extrinsic motivations: Classic definitions and new directions," Contemporary Educational Psychology, vol. 25, pp. 54-67, 2000.

[7] M. Vansteenkiste, E. Sierens, B. Soenens, K. Luyckx, and W. Lens, "Motivational profiles from a self-determination perspective: The quality of motivation matters," Journal of Educational Psychology, vol. 101, pp. 671-688, 2009.

[8] M. W. Eysenck and M. G. Calvo, "Anxiety and performance: The processing efficiency theory," Cognition and Emotion, vol. 6, pp. 409-434, 1992.

[9] T. Woodman and L. Hardy, "Stress and anxiety," in R. N. Singer, H. A. Hausenblas, a C. M. Janelle (Eds.), Handbook of Sport Psychology, 2nd ed., New York: Wiley, 2001, pp. 290-318.

[10] A. M. Cooke, "Effects of competition on performance, and the underlying psychophysiological mechanisms," Ph.D. dissertation, School of Sport and Exercise Sciences College of Life and Environmental Sciences, The University of Birmingham September 2010.

[11] R. Mullen, L. Hardy, and A. Tattersall, "The effects of anxiety on motor performance: A test of the conscious processing hypothesis," Journal of Sport and Exercise Psychology, vol. 27, pp. 212-225, 2005.

[12] Vienna Test System Psychological Assessment Catalog, 2012.

[13] M. W. Eysenck, "Anxiety, processing efficiency theory and performance," in Processes of the Molar Regulation of Behavior, W. Lengerich Battman, and S. Dutke: Pabst Science, 1996.

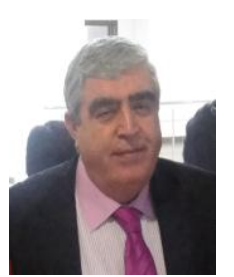

M. Aniței was born in Romania on October 18, 1948. He graduated Faculty of Psychology and Educational Sciences in 1974. He took his PhD in Psychology in 1990. Mr. Aniței has the following degree: bachelor's degree and master's degree paper coordinator; president of the Ph.D paper analysis committee; postdoctoral program coordinator at Faculty of Psychology and Educational Sciences, University of Bucharest. The author's major fields of study are the following: Experimental Psychology, Traffic Psychology, Cognitive Psychology, Organizational Psychology, Emotions, Cognition and Behavior, Management of Human Resources, Clinical Psychology, Environmental Psychology and Consumer behaviour Psychology. He is the President of the Collegium of the Psychologists from Romania and the director of the Doctoral School, Faculty of Psychology and Educational Sciences, University of Bucharest. Also he has the followings attributes: Director of Doctoral School, Faculty of Psychology, University of Bucharest, He wrote 8 books and more than 100 research papers and scientific studies published international conferences, Proceedings, national conferences and International and National Journals. Professor PhD M. Aniței has the following memberships: IEDRC, Romanian Collegium of Psychologists, the Romanian Society of Work, Organizational and traffic Psychology, the Romanian Society of Experimental Applied Psychology. 


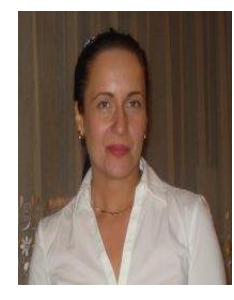

M. Chraif was born in Romania on February 14, 1974 She graduated Faculty of Psychology (2007-Faculty of Psychology and Educational Sciences, University of Bucharest) and Faculty of Economics, Financing and Accounting (2002- Titu Maiorescu University, Bucharest Romania) and also she graduated three masters programs: 1) Master in Financing and Capital Markets-2002-2004, Academy of Economic Sciences, Bucharest Romania; 2) Master in Organizational Psychology and human resources, University of Bucharest, Romania; 3) Clinical psychology and Cognitive behavioural psychotherapy, Titu maiorecu University, Bucharest, Romania. Also, she took her $\mathrm{PhD}$ in Cognitive Psychology applied to workplace and transportation psychology in 2009, Bucharest University, Romania. Since then she has constantly been working in the field teaching, research studies at the Faculty of Psychology and Educational Sciences, University of Bucharest. Since 2010 she is postdoctoral fellow in the strategic grant POSDRU/89/1.5/S/62259, E.U.
Project. She is coordinator of master degree dissertations. Also she has the followings attributes: Coordinator of the Master's Degree program:"Work and Transport Psychology", Coordinator of Work and Transportation Psychology Laboratory, Faculty of Psychology and Educational Sciences, University of Bucharest, Romania. She wrote 9 books and more than 100 research papers and scientific studies published at International Conferences, Proceedings, National Conferences and International and National Journals. The author published the main Current and previous research interests are the following: psychophysiology measured by polygraph, EEG studies, experimental psychology, changing behavior in different fields: traffic, work and organizational psychology, educational psychology, clinical psychology, stocks, financing. Lecturer PhD M. Chraif has the following memberships: IEDRC, Romanian Collegium of Psychologists, the Romanian Society of Work, Organizational and traffic Psychology, the Romanian Society of Experimental Applied Psychology, Romanian Association of Integrative Psychotherapy. 